\title{
Pronator Quadratus Muscle
}

National Cancer Institute

\section{Source}

National Cancer Institute. Pronator Quadratus Muscle. NCI Thesaurus. Code C150854.

A muscle that originates on the distal anteriomedial surface of the ulna and inserts in the distal anteriolateral surface of the radius; it is involved in the pronation of the forearm and is supplied by the anterior interosseous nerve and artery. 